\title{
Searching in the Pre-IPO Market-
}

\section{Interaction between Private Firms and Investment Banks}

\author{
Chung Chen ${ }^{1}$, Milena Petrova ${ }^{2} \&$ Garrison Hongyu Song ${ }^{3}$ \\ ${ }^{1}$ School of Statistics, Southwestern University of Finance and Economics, Chengdu, Sichuan, 610072, China \\ 2 Department of Finance, Whitman School of Management, Syracuse University, Syracuse, NY, 13244, USA \\ ${ }^{3}$ Department of Business Administration, School of Business, Mount St. Joseph University, Cincinnati, OH, 45233, \\ USA
}

Correspondence: Garrison Hongyu Song, Department of Business Administration, School of Business, Mount St. Joseph University, Cincinnati, OH, 45233. U.S.A.

Received: October 28, 2015

Accepted: November 5, $2015 \quad$ Online Published: November 10, 2015

doi:10.5430/afr.v4n4p147

URL: http://dx.doi.org/10.5430/afr.v4n4p147

\begin{abstract}
We are the first to set up a random search based model to describe the pre-IPO market searching and matching process between private firms with intent to sell equity in an IPO and investment banks (IB) that underwrite the issue. Due to the wide existence of the market search friction, the necessary time is required in order to form a strategic pair between a private firm and an investment bank for a successful IPO. We derive a closed-form formula for the investment bank's share of profit from an IPO transaction at the market equilibrium. The calibrated simulation result for this value is consistent with the "seven percent solution" initially identified by Chen and Ritter (2000). Our model suggests that IPO underpricing is not a deterministic phenomenon but an empirical observation, the existence of which largely originates from the market-wide co-movement between the total gross proceeds of each IPO and the total number of successful IPOs.
\end{abstract}

Keywords: IPO, Market search friction, IPO short-run underpricing, Private firm, Investment bank

\section{Introduction}

\subsection{Background}

In corporate finance, the research effort devoted to initial public offerings (IPOs) is unremitting not only because going public represents a crucial stage for the growth of a privately owned firm, namely broader financing channels along with more diversified control and ownership structures, but also because several intriguing phenomena along with an IPO process have not been fully explained yet (Ritter \&Welch, 2002; Carter, Dark, \&Singh, 1998).

A typical IPO process consists of three stages: pre-IPO stage, IPO, and post-IPO stage. While finance literature puts great emphasis on the latter two stages (IPO and post-IPO), the pre-IPO stage is largely unexamined. In another word, the interaction between private firms and investment banks in the pre-IPO market has not yet been studied in a systematic way. A better understanding of the dynamic searching and matching process in the pre-IPO market between them would enhance our analysis of IPO related puzzles since the order of events matters in this "sequential game", which is the motivation of the current study.

There is another advantage of the emphasis on the pre-IPO stage. The challenge of designing one systematic framework to deal with all IPO linked phenomena mainly stems from the "three- player game", i.e. there are three key types of players involved in an IPO transaction, namely, the issuing private firm, the investment bank, and the outside general investors. However, if we only focus on the pre-IPO stage, the "three-player game" can be transformed into the "two-player game", which may significantly reduce the degree of complexity of our analysis without losing any significance.

During the prolonged pre-IPO stage, there obviously exist intense searching and matching activities between private firms and investment banks. When any privately owned firm attempts to sell its equity for the first time at the primary security market, as its first move, the firm has to search for a proper leading investment bank to underwrite the issue (Even for Google which uses Dutch auction as its IPO method, it still has Morgan Stanley and Credit Suisse First 
Boston as its underwriters). When choosing an underwriter, the firm needs to consider multiple factors, including its own characteristics such as the size of the issue, the industry in which the firm operates, and the investment bank's characteristics such as the underwriter's reputation and expertise, etc. On the other hand, the investment bank has its own criteria to select which firm's issue it prefers to underwrite and then market under the constraint of limited human and financial resources in the house, not to mention the after-market price stabilization role played by the investment bank (Brav \& Gompers, 2003).

While asymmetric information based models seem to dominate the mainstream of IPO modeling literature (actually most of corporate finance theoretical models can be traced back to asymmetric information models), our model addresses the interaction between private firms and investment banks in the pre-IPO stage from a totally different viewpoint, i.e. a search-based angle. Asymmetric information models stereotypically assume that in any relevant game structure, there always exists one type of players who know more than the others (i.e. the information friction). Depending on the comparative information advantage of the different types of players, researchers can thus easily borrow such basic frameworks from economics as the "principal-agent" model if the investment bank has more information than the issuing private firm, the "moral hazard" model if the strategic pair composed of the investment bank and the issuing private firm knows more than the outside general investors, and finally, the "winner's curse" model when some investors (informed investors) are better informed than the other investors ( uninformed or noise investors), to explain the IPO related phenomena. (Since our model solely focuses on the pre-IPO stage, the asymmetric information mentioned before specifically means the information friction only between private firms and investment banks.) However, our model puts a sole stress on the market search friction, which doesn't mean that the issue of the asymmetric information between private firms and investment banks is not important. Unfortunately we, however, avoid it on purpose here to emphasize more important searching and matching characteristics of the market equilibrium that has largely been ignored in traditional corporate finance literature. Our searched based model has the ability to investigate the interaction of many private firms and many investment banks in the pre-IPO market, while a typical asymmetric information model is more targeted at the "one on one" bargaining process between one issuing private firm and one investment bank without a full consideration of the pressure from "peers".

The fact that the success of IPO depends not only on the effort of the private firm but also on the professional support of the investment bank has a far-reaching effect on the modeling of the pre-IPO market behaviors of both agents. Even though the financial market condition (e.g. the investor sentiment is high) is permitted, it still takes time (and/or other resources) for a private firm to locate a proper investment bank when the cooperation of both of them is of necessity to accomplish an IPO transaction. From the practical viewpoint, the market search friction exists more or less in any IPO process since there is simply no such thing as a 100 percent centralized market where two types of agents can meet and proceed instantly.

\subsection{Our Contributions and Literature Review}

In this paper, we construct a search-based theoretical model to describe the pre-IPO market searching and matching process between private firms with intent to sell equity in an IPO and investment banks (IB) that underwrite the issue. We expect that our model can amend the lost chain in current IPO studies. Our main theoretical contribution to IPO literature is that we introduce the market search friction to the modeling of the pre-IPO market optimal behaviors of both agents.

Firstly, our model provides a "search-based" interpretation why the initial offer price only partially adjusts up in response to the positive public information during the IPO price formation stage (or book-keeping stage). Our model points at the investment bank as the main culprit of this incomplete adjustment of the initial offer price. Our model shows that the full adjustment of the initial offer price to the positive public information always betters the welfare of the issuing private firm, but not always for the investment bank. It is probable that the investment bank's share of proceeds will shrink along with the increase in the initial offer price. Intuitively, due to the market-wide co-movement between the total gross proceeds of each IPO and the total number of successful IPOs, while the increased initial offer price means that the size of the "IPO pie" becomes larger, it could reduce the investment bank's proportion of the "IPO pie" much more seriously since going public for the private firm becomes less difficult, which will significantly weaken the professional role played by the investment bank in an IPO transaction. To one extreme scenario, the investment bank may even become totally useless, the effect of which is equivalent to the decrease in the investment bank's bargain power over the issuing private firm.

The phenomenon of the partial adjustment of the initial offer price to the positive public information is closely related to IPO short-run underpricing. IPO underpricing, the persistent positive significant average first day IPO returns, has drawn a voluminous research attempting to explain this observation. Logue (1973) and Ibbotson (1975) are among the 
first to record that share prices tend to increase substantially in the first day of trading. While there is a significant variation in the first day returns over time and by country during the period of 1960 to 2010 on average, the closing price at the end of the first day of trading for IPO shares is 16.8 percent above the offered price, which implies that a very large amount of "money left on the table" (Loughran \& Ritter, 2002). Based on a shorter period of time underpricing is less prominent, but still economically significant. Loughran and Ritter (2004) report an average initial return during the period of 1980-2003 of 6.3\%, with the highest underpricing of 32.3\% observed in 1999-2000. To some extent, IPO underpricing can be approximated by the difference between the first day closing price (which is largely affected by the current market sentiment of general investors) and the initial offer price (which is agreed upon by both the issuing private firm and the investment bank). Although our model never touches on the first day closing price of an IPO, our search-based model can simulate an IPO underpricing or deteriorate an already existed one if we assume that the positive public information will be fully reflected in the first day closing price while the same information can only lead to less amount of adjusting-up in the initial offer price under the influence of the investment bank.

Secondly, our search-based model offers an alternative innovative approach to studying the dynamics of IPO activities without the assumption of asymmetric information, while the patterns of IPO activities are traditionally explained by the market-timing theory initially developed by Lucas and McDonald (1990), who study the firm's decision to issue equity when information asymmetry regarding the value of assets in place exists. Based on the market-timing view issuers tend to postpone equity sales until good market conditions, when they are able to sell overpriced equity. This notion has been supported by Baker and Wurgler (2000) who document that equity issues are negatively correlated with future market returns.

This paper exemplifies one application of search theory in corporate finance. In macroeconomics and labor economics search theory is widely used to explore the matching behavior between workers and firms (Diamond, 1984; Mortensen \&Pissarides, 1994; Jacquet \&Tan, 2007; Shimer, 2007; Menzio, 2007). Although search theory is popular in economics represented by the fact that the 2010 Nobel prize in economics was jointly awarded to Diamond, Mortensen, and Pissarides "for their analysis of markets with search frictions" and the 2012 Nobel prize in economics to Roth and Shapley "for the theory of stable allocations and the practice of market design", it has been not used in the corporate finance literature, with very few exceptions. Silveira and Wright (2007) propose a search-based model to study the venture capital cycle. In their model, the capitalists (with funds) and entrepreneurs (with technical expertise) are searching in a de-centralized venture capital market. They analyze the duration of each phase in the cycle and the flow of funds into the market.

Duffie, Garleanu \& Pedersen (2002, 2005 and 2007), and Lagos and Rocheteau (2007) are pioneers to introduce search theory to dynamic asset markets. Vayanos and Weill (2008) propose a search-based model to explain the on- the- run phenomenon in the over-the counter (OTC) fixed income markets. Their model shows that assets with identical cash flows can trade at different prices due to the existence of short-sellers and search frictions in the spot and the repo markets.

This paper is also related to but fundamentally different from Fernando, Gatchev, \& Spindt's (2005) matching model in which issuers and underwriters associate by mutual choice and matches are based on firms' and underwriters' relative characteristics at the time of issuance. But they never put the market search friction into consideration when modeling the searching and matching process in the pre-IPO market, thus losing a track of the general picture of IPO processes.

Yung, Çolak \& Wang(2008) set up an asymmetric information based model to interpret the highly positive correlation between the volume of IPOs and the IPO underpricing. Liu and Ritter (2011) develop a theory about IPO underpricing when issuers care about the non-price aspect of underwriting under the market structure of localized competition. Hanley and Hoberg (2012) find that issuers may use underpricing and strategic disclosure to hedge against litigation risk while underwriters can experience the loss of market share if they fail to adequately hedge against litigation risk.

Recent research about IPO activities has extended from the U.S. to other countries. For instance, Chambers and Dimson's (2009) study covers British IPOs since World War I. They find that there is a huge fluctuation for the magnitude of the IPO underpricing over this very long period. Kutsuna, J. Smith, \& R. Smith's (2009) study focuses on Japanese IPOs. Their paper indicates that offer prices is the result of implicit agreement between issuers and underwriters and reflects the pre-IPO market values of public companies.

The rest of this paper proceeds as follows: section 2 describes the pre-IPO search model; section 3 sets up the model mathematically and discusses major theoretical results derived from it; section 4 analyzes the empirical implications of the model, calibrates the model and shows the simulation results; section 5 concludes. 


\section{A pre-IPO Search Model}

In this section, we describe a stylized pre-IPO market including homogeneous private firms (denoted by f) whose final aim is always to go public at a good timing, and homogeneous investment banks (denoted by b), the support of which is of necessity for the success of an IPO. The initial number of private firms is normalized to 1 and the initial number of investment banks is $\mathrm{n}$ (the value of $\mathrm{n}$ is usually much smaller than 1). We assume that at a given time period each private firm (f) can only hire one investment bank (b) to underwrite its IPO and each investment bank can only serve one private firm customer.

Those two types of agents are continuously meeting with each other according to a standard Poisson process with meeting rates of $\alpha_{\mathrm{f}}$ and $\alpha_{\mathrm{b}}$, respectively, Hence, on average, during each period each private firm will meet $\alpha_{\mathrm{f}}$ number of investment banks and each investment bank will meet $\alpha_{b}$ number of private firms. The values of $\alpha_{f}$ and $\alpha_{b}$ cannot be infinite, which characterizes the presence of the search friction existing in the pre-IPO market. The values of $\alpha_{\mathrm{f}}$ and $\alpha_{\mathrm{b}}$ will ultimately depend on the relative number of private firms and investment banks in the market, i.e. the market tightness. The reciprocals of $\alpha_{f}$ and $\alpha_{b}\left(1 / \alpha_{f}\right.$ and $\left.1 / \alpha_{b}\right)$ thus represent the expected meeting time, accounting for not only the time spent on searching, but also the time consumed in the negotiation process by the two agents. Furthermore, the magnitude of these two parameters can even reflect some type of hindrance originated from asymmetric information and the heterogeneity of private firms and investment banks.

The private firm and the investment bank simultaneously decide whether to form a strategic pair or not when meeting with each other. If either agent doesn't agree to form a pair, there will not be an IPO later. Some reasons for a private firm to decline to form this pair include: the private firm waits for another better offer from another investment bank; or the private firm waits for another good timing to go public. The same logic applies to the consideration of the investment bank. If the private firm and the investment bank both agree to form a strategic pair, the investment bank will require a profit of $\mathrm{k}$, representing any underwriting related service fees such as the commission fee and other un-named benefits, and the private firm will keep the residual part(R-k), both due when the IPO with the total gross proceeds of $\mathrm{R}$ succeeds in the future. In our model, we assume that each firm can only issue one share of stock. Thus we ignore the problem of how many shares will be outstanding for an IPO. In this way the total gross proceeds of an IPO can be considered as the initial offer price of an IPO as well.

The investment bank's profit $\mathrm{k}$ is the result of bargaining between the private firm and the investment bank when meeting with each other. We utilize the generalized Nash bargaining scheme to pin down the value of $\mathrm{k}$, assuming that the investment bank's bargaining power is characterized by $\theta$. The value of $\theta$ falls between 0 and 1 . When $\theta$ approaches to 1 indicating that the investment bank has a higher bargaining power over the private firm and therefore, it can claim a larger amount of the profit from any fixed amount of the total IPO proceeds and vice versa.

We assume that the occurrence of successful IPOs follows another standard Poisson process with a success arrival rate of $\sigma$, i.e. on average during each period there are $\sigma$ number of successful IPOs among all proposed IPOs. The value of $\sigma$ cannot be infinite either, which implies the concern that any IPO promoted by a strategic pair formed by a private firm and an investment bank is not guaranteed to be successful in the real world. According to a report of a consulting firm Dealogic, nearly 300 initial public offerings, valued at almost $\$ 60$ billion, were withdrawn in 2008. That's almost double the number from 2007. Generally speaking, the current macroeconomic environment, the financial market condition and even the advertising effort of investment banks can all influence the magnitude of $\sigma$, e.g. the looser the credit policy of the Federal Reserve System, the more optimistic the current stock market and the more intense the investment banks' underwriting activities, and hence the higher the value of $\sigma$. Once an IPO succeeds, the investment bank will return to the market and the private firm will exit the market. Moreover, a clone of the private firm will refill the market to keep the market equilibrium in the language of search theory.

In addition, we assume that both types of agents are risk neutral and the market on-going (risk-free) discount rate is denoted as $r$, which characterizes the time preference of private firms and investment banks.

In sum, the entire pre-IPO process can be illustrated by Figure 1. In the pre-IPO market, private firms and investment banks can stay in two distinct states: the searching state where private firms and investment banks meet and negotiate with each other and the pair state where the strategic pair formed by one private firm and one investment bank waits for the success of the IPO. 


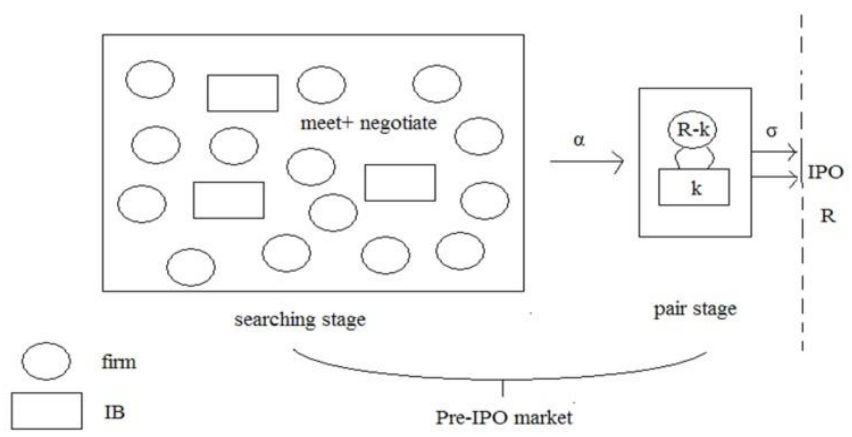

Figure 1. The general picture of the pre-IPO market

Since there are two types of agents ( $b$ denotes the investment bank and $f$ denotes the private firm) and two states ( 0 indicates the searching state sand 1 indicates the pair state), we thus define four state value functions:

$\mathrm{V}_{\mathrm{f}}{ }^{\mathrm{o}}$ : the value of a private firm who is searching an investment bank in the market;

$\mathrm{V}_{\mathrm{f}}{ }_{\mathrm{f}}$ : the value of a private firm who forms a strategic pair with an investment bank;

$\mathrm{V}_{\mathrm{b}}{ }^{0}$ : the value of an investment bank who is searching a private firm in the market;

$\mathrm{V}_{\mathrm{b}}{ }^{1}$ : the value of an investment bank who forms a strategic pair with a private bank.

These four value functions represent corresponding "utilities" or "welfares" obtained when staying in those two states for those two types of agents, respectively.

\section{Mathematical Model and Discussion}

\subsection{Basic Model Set-up}

In this section, we apply the Bellman equations to analyze the pre-IPO process between private firms and investment banks. We will derive a closed-form formula for the investment bank's share of profit from the IPO transaction at the market equilibrium and discuss its empirical implications.

Since there are two types of agents, private firms and investment banks who are continuously searching in the pre-IPO market, the interaction between them is thus modeled as a two-sided search, in contrast to a one-sided search where only one type of agents is actively searching in the market and the counterparty is just idle.

For this case, we assume that there doesn't exist any uncertainty about the total gross proceeds or the initial offer price $(\mathrm{R})$. Both agents know the exact value of $\mathrm{R}$ before playing the game. If the market prevalent value of the investment bank's share of profit is $\mathrm{k}^{*}$, the four value functions defined in Section 1 satisfy the below four search equations:

$$
\begin{gathered}
r V_{f}^{o}=\alpha_{f}\left(V_{f}^{1}-V_{f}^{o}\right) \\
r V_{f}^{1}=\sigma\left(R-k^{*}-V_{f}^{1}\right) \\
\mathrm{r} \mathrm{V}_{b}{ }^{o}=\alpha_{b}\left(V_{b}{ }^{1}-V_{b}{ }^{o}\right) \\
\mathrm{r} \mathrm{V}_{b}{ }^{1}=\sigma\left(k^{*}+V_{b}{ }^{0}-V_{b}{ }^{1}\right)
\end{gathered}
$$

All four equations have the similar structure: the left hand side is called the flow value, which is always the product of the discount rate and the value for each specific state; the right hand side is the expected value change from the agent's current state, which is the product of the state-jump rate (such as $\alpha_{\mathrm{f}}, \alpha_{\mathrm{b}}$ and $\sigma$ ) and the value change from the agent's current state. For instance, for Equation (1), the left hand side represents the flow value for a private firm who is searching an investment bank in the market; the right hand side is the private firm's expected value change jumping from the searching state to the pair state.

We then define two surplus functions, $S_{\mathrm{f}}$ and $S_{\mathrm{b}}$, for private firms and investment banks separately. Those functions will be used during the private firm and investment bank's bargaining process to help us form an objective function under the framework of generalized Nash bargaining scheme. 


$$
\begin{gathered}
S_{f}=V_{f}{ }^{1}-V_{f}{ }^{o} \\
S_{b}=V_{b}{ }^{1}-V_{b}{ }^{o}
\end{gathered}
$$

Given the market prevalent value of the investment bank's share of profit $\mathrm{k}^{*}$ and the investment bank's bargaining power $\theta$, we apply the generalized Nash bargaining scheme to divide the initial offer price (or the total gross proceeds) $\mathrm{R}$ between the private firm and the investment bank through solving a Cobb-Douglas like utility maximization problem with the choice variable of the investment bank's share of profit k. Although it does not provide the detailed bargaining process, the generalized Nash bargaining scheme is simple and convenient to use for theoretical analysis.

$$
\operatorname{Max} \mathrm{S}_{\mathrm{f}}{ }^{1-\theta} \mathrm{S}_{\mathrm{b}}{ }^{\theta} \quad \text { by choosing k. }
$$

The market equilibrium requires that the market prevalent value of $\mathrm{k}^{*}$ be squarely consistent with each investment bank's share of profit $\mathrm{k}$ resulted from the general Nash bargaining scheme:

$$
\mathrm{k}=\mathrm{k}^{*}
$$

Linking the above eight equations from Equation (1) to (8), we can solve for eight variables $\left(\mathrm{V}_{\mathrm{f}}{ }^{\mathrm{o}}, \mathrm{V}_{\mathrm{f}}{ }^{1}, \mathrm{~V}_{\mathrm{b}}{ }^{\mathrm{o}}, \mathrm{V}_{\mathrm{b}}{ }^{1}, \mathrm{~S}_{\mathrm{f}}, \mathrm{S}_{\mathrm{b}}\right.$, $\left.\mathrm{k}, \mathrm{k}^{*}\right)$ as a function of six model parameters $\left(\alpha_{\mathrm{f}}, \alpha_{\mathrm{b}}, \mathrm{r}, \sigma, \theta, \mathrm{R}\right)$.

Further calculations provide a closed form formula for the investment bank's share of profit $\mathrm{k}^{*}$ from the IPO transaction at the market equilibrium. Proposition 1 summarizes this result.

Proposition 1: The market prevalent value of the investment bank's share of profit $k^{*}$ at the market equilibrium is expressed by Equation (9)

$$
k^{*}=\frac{\theta r\left(r+\sigma+\alpha_{b}\right)}{\theta r\left(r+\sigma+\alpha_{b}\right)+(1-\theta)(r+\sigma)\left(r+\alpha_{f}\right)} R
$$

Comparative statics analysis can be applied to Equation (9) to study the impact of different parameters on the investment bank's share of profit at the market equilibrium. We will focus on those five key parameters: $\alpha_{\mathrm{b}}, \alpha_{\mathrm{f}}, \theta, \sigma$ and R. When doing partial derivatives on Equation (9), we find that $\frac{\partial \mathrm{k}}{\partial \alpha_{\mathrm{f}}}<0$ and $\frac{\partial \mathrm{k}}{\partial \sigma}<0$ while $\frac{\partial \mathrm{k}}{\partial \alpha_{\mathrm{b}}}>0, \frac{\partial \mathrm{k}}{\partial \theta}>0$ and $\frac{\partial \mathrm{k}}{\partial \mathrm{R}}>0$. Those results are included in Corollary 1. Intuitively, $\alpha_{\mathrm{f}}$ and $\alpha_{\mathrm{b}}$ characterize the market searching condition. If an investment bank can meet more private firms during each time period, (corresponding to the case that a private firm can meet fewer investment banks during the same time period,) the market searching condition is benign to the side of the investment bank who will obtain more share of profit for each successful IPO transaction. In the meantime, $\sigma$ typifies the market condition for the strategic pair state. The faster the success arrival rate of IPO, the less important the role played by the investment bank in an IPO transaction. In the extreme case that the success arrival rate of IPO goes to infinity, the private firm even does not need the expertise from the investment bank in order to go public. Regarding to this logic, the increase in the success arrival rate of IPO is equivalent to the decrease in the investment bank's bargaining power. Thus the investment bank's share of profit should decrease with the increase in the value of the success arrival rate of IPO $(\sigma)$.In addition, if the initial offer price $(\mathrm{R})$ becomes larger and the investment bank has more bargaining power $(\theta)$ over the private firm, that the investment bank will acquire more share of profit is obvious.

Corollary 1: Ceteris paribus, the market prevalent value of the investment bank's share of profit $k^{*}$ at the market equilibrium is:(1) positively related to the meeting rate of an investment bank to a private firm $\left(\alpha_{b}\right)$; (2) negatively relatively to the meeting rate of a private firm to an investment bank $\left(\alpha_{f}\right) ;(3)$ positively related to the bargaining power of the investment bank $(\theta)$; (4) negatively related to the success arrival rate of IPO( $\sigma)$; and (5) positively related to the initial offer price $(R)$.

One unique issue is associated with the net effect of the initial offer price (or the total gross proceeds) $\mathrm{R}$ on the investment bank's share of profit $\mathrm{k}^{*}$ at the market equilibrium. Corollary 1 only indicates that, all else equal, the investment bank's share of profit is positively related to the initial offer price due to the positive sign of the partial derivative of $\mathrm{k}$ with respect to $\mathrm{R}$ (i.e. $\frac{\partial \mathrm{k}}{\partial \mathrm{R}}>0$ ), which means that the higher the initial offer price of IPO, the more profit the investment bank will earn from its service; moreover, the ratio of that profit to the initial offer price does not change along with the initial offer price (i.e. $\frac{\mathrm{k}}{\mathrm{R}}=$ fixed).

Proposition 2 deals with the total derivative of $\mathrm{k}$ with respect to $\mathrm{R}$ when the market-wide dynamics of IPO activities are introduced. Since in reality we often observe the co-movement between the total gross proceeds of an IPO and the total number of successful IPOs, for instance, during the boom of the IPO market, the higher amount of the total gross proceeds from an IPO is always accompanied by the larger number of successful IPOs while the relatively lower total 
gross proceeds follow the smaller number of them during the bust period, we assume that the success arrival rate $(\sigma)$ of IPO is positively related to the initial offer price $(\mathrm{R})$ in our model.

Specifically, let $\sigma$ be an increasing function of R, i.e. $\sigma=\sigma(R)$ and $\frac{d \sigma}{d R}>0$, the sign of $\frac{d k}{d R}$, i.e. the net effect of $R$ on $k$ cannot be determined without ambiguity since we have to consider two conflicting effects together now. The first effect is the "size effect", also called the direct effect of $\mathrm{R}$ on $\mathrm{k}$, which has already proved to be positive in Corollary 1.The second effect is the "ratio effect", also called the indirect effect transmitted through $\sigma$ when R changes, which is negative insofar as the increase in the success arrival rate of IPO is equivalent to the decrease in the investment bank's bargaining power. Only if the positive "size effect" dominates the negative "ratio effect" will the investment bank's share of profit increase when the initial offer price increases.

While the similar procedure is applied to the analysis of the net effect of the initial offer price $\mathrm{R}$ on the private firm's share of profit (i.e. the residual part) R-k, the conclusion is unequivocal: the sign of $\frac{d(R-k)}{d R}$ is always positive. Not only does the size of the "IPO pie" become larger, but the proportion of the private firm's share of profit also increases when confronting a higher initial offer price $\mathrm{R}$.

Those results are summarized in Proposition 2:

Proposition 2: When considering the market-wide dynamics of IPO activities, i.e. when the success arrival rate of $I P O(\sigma)$ is positively related to the initial offer price $(R)$, the relatively lower initial offer price $(R)$ could be beneficial to the investment bank, but not to the private firm.

Proposition 2 sheds light on IPO short-run underpricing. The crudest measure of IPO underpricing is the difference between the first day closing price (which is largely affected by the post-IPO investor sentiment) and the initial offer price (which is agreed upon by the issuing private firm and the underwriter). In other words, either the initial offer price is low or the first day closing price is high or both so as to have the phenomenon of IPO underpricing. While it is out of our reach to explain why the first day closing price is high, our search-based model can explain why the initial offer price could be relatively lower than it should have.

As we know, IPO underpricing is closely related to the observed phenomenon that the initial offer price only partially adjusts to the positive public information during the IPO book keeping process. Let's do a mental experiment in the pre-IPO stage to illustrate this process. As the starting point, suppose that the "imagined" first day closing price $\left(\mathrm{P}_{0}\right)$ is equal to the "tentative" initial offer price $\left(\mathrm{R}_{0}\right)$, there will squarely be no underpricing according to our simple definition of IPO underpricing above $\left(\mathrm{P}_{0}-\mathrm{R}_{0}=0\right)$. Furthermore, suppose that during the IPO book-keeping process some positive public information is released. If the information is expected to lead to the same amount of increase $(\varepsilon)$ in the new first day closing price $\left(\mathrm{P}_{1}=\mathrm{P}_{0}+\varepsilon\right)$ and in the new initial offer price $\left(\mathrm{R}_{1}=\mathrm{R}_{0}+\varepsilon\right)$, then there will still be no underpricing since $\mathrm{P}_{1}-\mathrm{R}_{1}=\left(\mathrm{P}_{0}+\varepsilon\right)-\left(\mathrm{R}_{0}+\varepsilon\right)=\mathrm{P}_{0^{-}} \mathrm{R}_{0}=0$. This phenomenon is called the fully adjustment of the initial offer price in respond to the positive public information. However, if the new initial offer price is only partially adjusted up, for instance, when the new first day closing price increases by $\varepsilon$ and the new initial offer price only increases by $0.5 \varepsilon$ (due to the interaction between the private firm and the investment bank in the pre-IPO market), there will be an underpricing of $0.5 \varepsilon$ since $\mathrm{P}_{1}-\mathrm{R}_{1}=\left(\mathrm{P}_{0}+\varepsilon\right)-\left(\mathrm{R}_{0}+0.5 \varepsilon\right)=0.5 \varepsilon>0$.

Proposition 2 implies that the driving force of IPO underpricing mainly comes from the investment bank's side since the relatively lower initial offer price could be beneficial to the investment bank, but not to the private firm. Borrowing our previous analysis of the size effect and the ratio effect when the initial offer price $\mathrm{R}$ increases, if the ratio effect dominates the size effect, the highest achievable value of the initial offer price is not always an optimal choice from the viewpoint of the investment bank, while it is always better for the private firm to face a higher initial offer price.

Another important issue related to Proposition 2 is the uncertainty of IPO underpricing. As we have discussed before, we cannot deny the capacity of our model to interpret IPO underpricing. However, we have to admit that IPO underpricing is more as an empirical or statistical phenomenon than as a deterministic one since our model also shows that when the size effect dominates the ratio effect, the full-adjustment of the initial offer price or even the overadjustment of it in respond to the positive public information is highly probable. In this way, we do observe some IPOs showing "overpricing" (i.e. the first day closing price is lower than the initial offer price.) Our model's prediction is consistent with the finding by Lowry, Officer \& Schwert (2010) that the monthly volatility of IPO initial returns is substantial. As one of the most recent examples, Facebook (FB) priced its IPO at \$38 per share on May, 17, 2012. However, the average of the first five-day closing prices of FB is only $\$ 33.66$ per share, which represents a negative return of $-11.42 \%$. 


\subsection{Endogenization of Two Meeting Rates of $\alpha_{f}$ and $\alpha_{b}$}

The above content is basically a partial equilibrium search model with the two meeting rates of $\alpha_{\mathrm{f}}$ and $\alpha_{\mathrm{b}}$ as parameters of the model. More interestingly, the meeting rates of $\alpha_{\mathrm{f}}$ and $\alpha_{\mathrm{b}}$ can be endogenized once we apply the balanced steady state flow condition to the system shown in Figure 2.

Recall that initially the number of private firms is normalized to 1 and the number of investment banks is $\mathrm{n}$. Let the number of the strategic pairs be $\mathrm{m}$ at the steady state, thus the number of un-paired private firms is $1-\mathrm{m}$ and the number of un-paired investment banks is $n-m$ at the steady state then. The balanced steady state flow condition requires that:

$$
(1-\mathrm{m}) \alpha_{\mathrm{f}}=\sigma \mathrm{m}=(\mathrm{n}-\mathrm{m}) \alpha_{\mathrm{b}}
$$

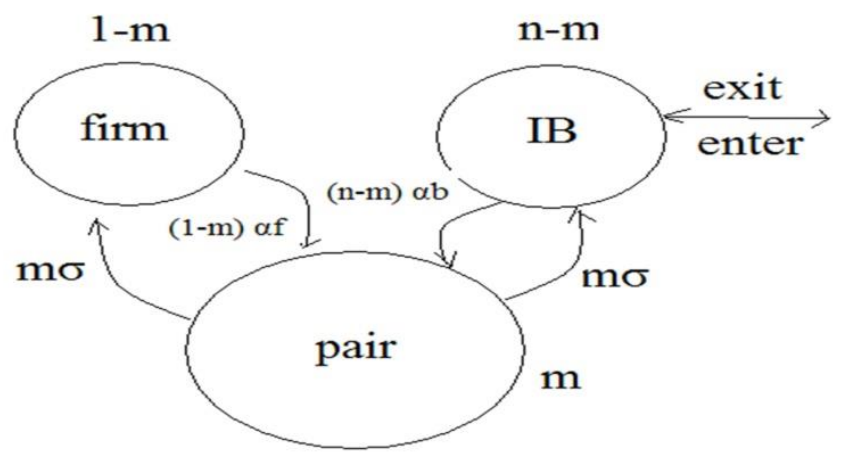

Figure 2. The balanced steady state flow

Define the market tightness (MT) as the relative number of investment banks and private firms at the steady state:

$$
\mathrm{MT}=\frac{\mathrm{n}-\mathrm{m}}{1-\mathrm{m}}
$$

The matching technology between private firms and investment banks is reflected in a matching function denoted as $\pi$ that depends on the numbers of both types of agents in the pre-IPO market. Assuming that $\pi$ has a constant rate of return with respect to those two numbers and has a functional form in Equation (12)( $\delta$ is a parameter which is less than 1), the meeting rates of $\alpha_{\mathrm{f}}$ and $\alpha_{\mathrm{b}}$ can thus be expressed as a function of the market tightness MT in Equation (13) and (14):

$$
\begin{aligned}
\pi & \equiv \pi(1-\mathrm{m}, \mathrm{n}-\mathrm{m}) \equiv(1-\mathrm{m})^{1-\delta}(\mathrm{n}-\mathrm{m})^{\delta} \\
\alpha_{\mathrm{f}} & \equiv \pi /(1-\mathrm{m})=(1-\mathrm{m})^{-\delta}(\mathrm{n}-\mathrm{m})^{\delta}=\mathrm{MT}^{\delta} \\
\alpha_{\mathrm{b}} & \equiv \pi /(\mathrm{n}-\mathrm{m})=(1-\mathrm{m})^{1-\delta}(\mathrm{n}-\mathrm{m})^{\delta-1}=\mathrm{MT}^{\delta-1}
\end{aligned}
$$

To close up our model, we need to assume the free entry for investment banks to the underwriting industry, which requires that the value of investment banks searching in the pre-IPO market be a fixed value of staying out of this market, L:

$$
\mathrm{V}_{\mathrm{b}}{ }^{\mathrm{o}}=\mathrm{L}
$$

In sum, this extended general equilibrium search model consists of Equation (1)-(8) and Equation (10)-(15). We can solve for thirteen variables $\left(\mathrm{V}_{\mathrm{f}}{ }^{\mathrm{o}}, \mathrm{V}_{\mathrm{f}}{ }^{1}, \mathrm{~V}_{\mathrm{b}}{ }^{\mathrm{o}}, \mathrm{V}_{\mathrm{b}}{ }^{1}, \mathrm{~S}_{\mathrm{f}}, \mathrm{S}_{\mathrm{b}}, \mathrm{k}, \mathrm{k}^{*}, \alpha_{\mathrm{f}}, \alpha_{\mathrm{b}}, \mathrm{n}, \mathrm{m}, \mathrm{MT}\right)$ as a function of six model parameters $(\mathrm{r}$, $\sigma, \theta, \delta, \mathrm{R}, \mathrm{L})$.

Proposition 3: The pre-IPO market is characterized by two equilibrium equations: one is the investment bank's profit condition (16) and the other is the investment bank's free entry condition (17)

$$
=\frac{\theta r\left(r+\sigma+M T^{\delta-1}\right)}{\theta r\left(r+\sigma+M T^{\delta-1}\right)+(1-\theta)(r+\sigma)\left(r+M T^{\delta}\right)} R
$$




$$
L=\frac{\theta \sigma M T^{\delta-1} R}{\theta r\left(r+\sigma+M T^{\delta-1}\right)+(1-\theta)(r+\sigma)\left(r+M T^{\delta}\right)}
$$

Moreover, the number of IPO pairs at the market equilibrium is:

$$
m=\frac{M T^{\delta}}{\sigma+M T^{\delta}}
$$

the number of un-paired private firms at the market equilibrium is:

$$
1-m=\frac{\sigma}{\sigma+M T^{\delta}}
$$

the number of un-paired investment banks at the market equilibrium is:

$$
n-m=\frac{\sigma M T}{\sigma+M T^{\delta}}
$$

the initial number of investment banks which can be supported by the underwriting industry is:

$$
n=\frac{\sigma M T+M T^{\delta}}{\sigma+M T^{\delta}}
$$

Proposition 3 concludes our search based model. One of the key variables determined by this model is the market tightness MT, represented by the ratio of the number of investment banks to the number of private firms. The higher the value of the market tightness is, the more quickly for a private firm to find its underwriting investment bank. The market tightness MT can be solved directly from Equation (17). Once MT is resolved, the investment bank's share of profit $\mathrm{k}$ can be obtained from Equation (16). More importantly, the initial number of investment banks $\mathrm{n}$ can also be easily acquired based on Equation (21). Since the initial number of private firms is normalized to 1, the magnitude of the initial number of investment banks will represent the competitiveness of the underwriting industry. Therefore, Proposition 3 can be used to estimate how many investment banks can be supported in the underwriting industry by the IPO market.

\section{Empirical Implications}

In this section, we first calibrate the key parameters of our model according to the typical data from IPO markets. Then we combine the theoretical predictions of our model with the simulation results to illustrate the empirical implications of our model. Our results show that our search based model fits well into the real market.

\subsection{Parameter Calibration}

We use the median number of IPOs per month from 1980 to 2011 as the success arrival rate of IPO. So we choose 15 times per month for $\sigma$. The reason why we don't use the mean is because the median excludes the extreme effects of the stock market crisis such as 1998-1999 and 2008-2009. Without additional information, we always assume that the matching parameter $\delta$ and the investment bank's bargaining power $\theta$ are 0.5 . While we could use the current risk-free interest rate as the discount rate $r$ in our model, since the current risk-free interest rate is almost zero, we choose the median of monthly 10-year Treasury constant maturities nominal yields from January, 1980 to December, 2011, which is approximately $0.5 \% /$ month, as the discount rate applied in our model. Moreover, estimating the values of the two meeting rates $\alpha_{b}$ and $\alpha_{\mathrm{f}}$ is not an easy task. We apply two approaches here:

In the first approach, we apply Equation (11) and (13) to estimate those two meeting rates. Assuming that there are initially 1000 private firms and 20 investment banks in a typical pre-IPO market, 10 IPO strategic pairs will be formed during each month. Translated into our model's language, the initial number of private firms is normalized to 1, then the initial number of investment banks $n$ is $20 / 1000=0.02$ and the number of strategic pairs $m$ is $10 / 1000=0.01$. Using Equation (11), the market tightness will be $(0.02-0.01) /(1-0.01)=0.0101$; using Equation (13), the meeting rate of a private firm to an investment bank $\alpha_{\mathrm{f}}$ will be $0.0101^{0.5}=0.1005 \approx 0.1 /$ month and the meeting rate of an investment bank to a private firm $\alpha_{b}$ will be $0.0101^{-0.5}=9.95 \approx 10$ /month. As we assume that the matching parameter $\delta$ equals $0.5, \alpha_{b}$ is actually the reciprocal of $\alpha_{\mathrm{f}}$ according to Equation (13) and (14).

In the second approach, we use Equation (10) to estimate the meeting rate of an investment bank to a private firm $\alpha_{b}$. The basic pre-IPO market structure is that the number of private firms is much larger than that of investment banks. So 
it is more likely the meeting rate of a private firm to an investment bank is the controlling step for the searching state (please compare the values of $\alpha_{\mathrm{f}}$ with $\alpha_{\mathrm{b}}$ to see this point). In addition, for most IPO cases, when a private firm and an investment bank form a strategic pair, the success of this IPO is almost expected as long as the strategic pair is patient to wait for its turn. Thus we can reasonably assume that the meeting rate of an investment to a private firm is approximately equal to the success arrival rate of IPO. In sum, the three important rates have such a relationship as: $15=\sigma \approx \alpha_{\mathrm{b}}>>\alpha_{\mathrm{f}}=1 / \alpha_{\mathrm{b}}$.

Combining those two approaches, we thus choose 10 times per month as the meeting rate of an investment bank to a private firm. The meeting rate of a private firm to an investment bank will be $1 / 10=0.1$ times per month.

Table 1 summarizes the key parameters and their typical values used in our model simulation.

Table 1. Parameters and Their Values Used in the Model

\begin{tabular}{lll}
\hline Parameter & Notation & Typical Value \\
\hline The success arrival rate of IPO & $\sigma$ & $15 /$ month \\
The parameter in the matching technology function $\pi$ & $\delta$ & 0.5 \\
The (risk-free)discount rate & $\mathrm{r}$ & $0.5 \% /$ month \\
The investment bank's bargaining power & $\theta$ & 0.5 \\
The meeting rate of an investment bank to a private firm & $\alpha_{\mathrm{b}}$ & $10 /$ month \\
The meeting rate of a private firm to an investment bank & $\alpha_{\mathrm{f}}$ & $0.1 /$ month \\
\hline
\end{tabular}

\subsection{Simulation Results}

Before going to the detailed simulation results, our model shows that the investment bank's relative share of profit from an IPO transaction at the market equilibrium $(\mathrm{k} / \mathrm{R})$ is $7.35 \%$ when simply plugging the calibrated values of model parameters in Table 1 into Equation (9). This result is well consistent with the "seven percent solution" initially identified by Chen and Ritter (2000).

Figure 3 (a) and (b) show the effects of the market search efficiency $\left(\alpha_{f}\right.$ or $\left.\alpha_{b}\right)$ on the investment bank's relative share of profit $(\mathrm{k} / \mathrm{R})$ when the values of the other parameters in Table 1 are fixed. In Figure 3(a), the meeting rate of an investment bank to a private firm changes from 5 times per month to 20 times per month and in Figure3(b) the meeting rate of a private changes from 0.2 times per month to 0.05 per month. Consistent with Corollary 1, Figure 3 illustrates that the faster the meeting rate of an investment bank to a private firm and the slower the meeting rate of a private firm to an investment bank, the higher the investment bank's relative share of profit from an IPO at the market equilibrium.

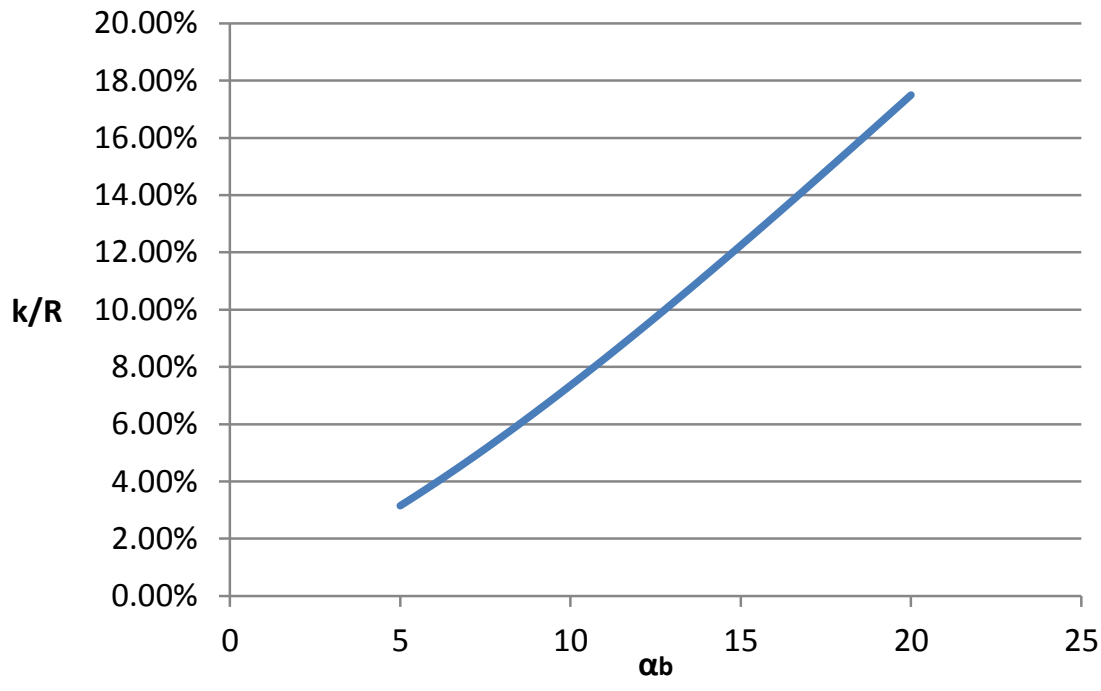

(a) 


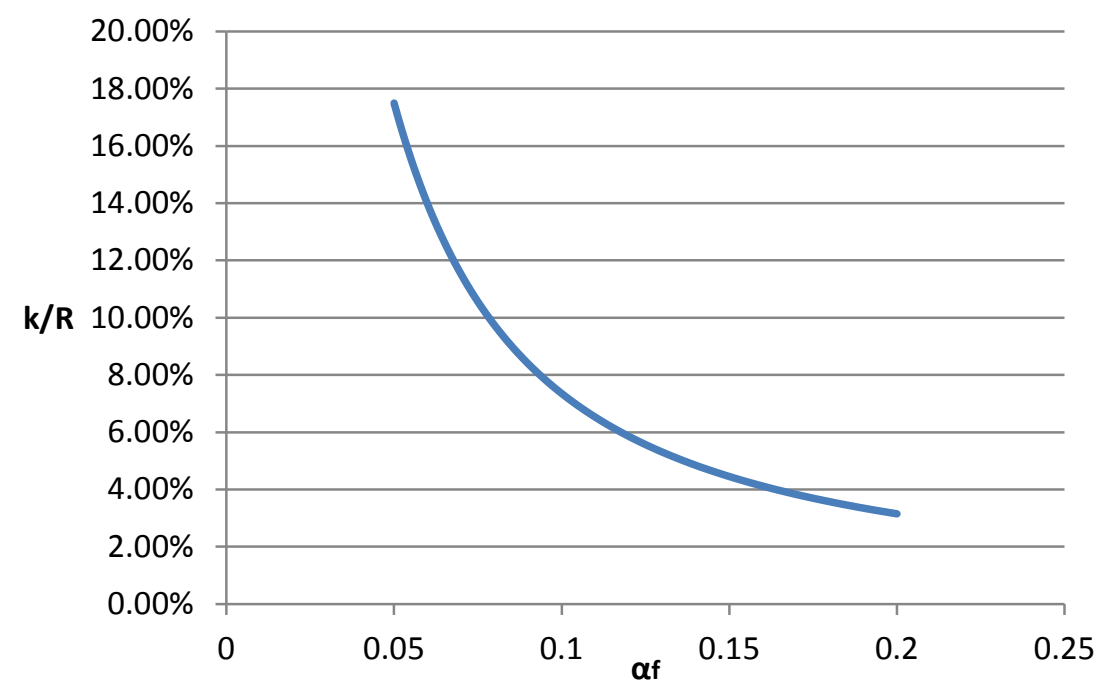

(b)

Figure 3. The effects of the market search efficiency on the investment bank's relative profit

Figure 4 shows the effect of the investment bank's bargaining power on the investment bank's relative share of profit when the values of the other parameters in Table 1 are fixed. When the investment bank's bargaining power changes from 0.1 to 0.9 , we can see that the investment bank's relative share of profit increases significantly. In a real pre-IPO market, the investment bank's bargaining power will be a crucial factor affecting its profit earning ability. But this value can fluctuate case by case and industry by industry,

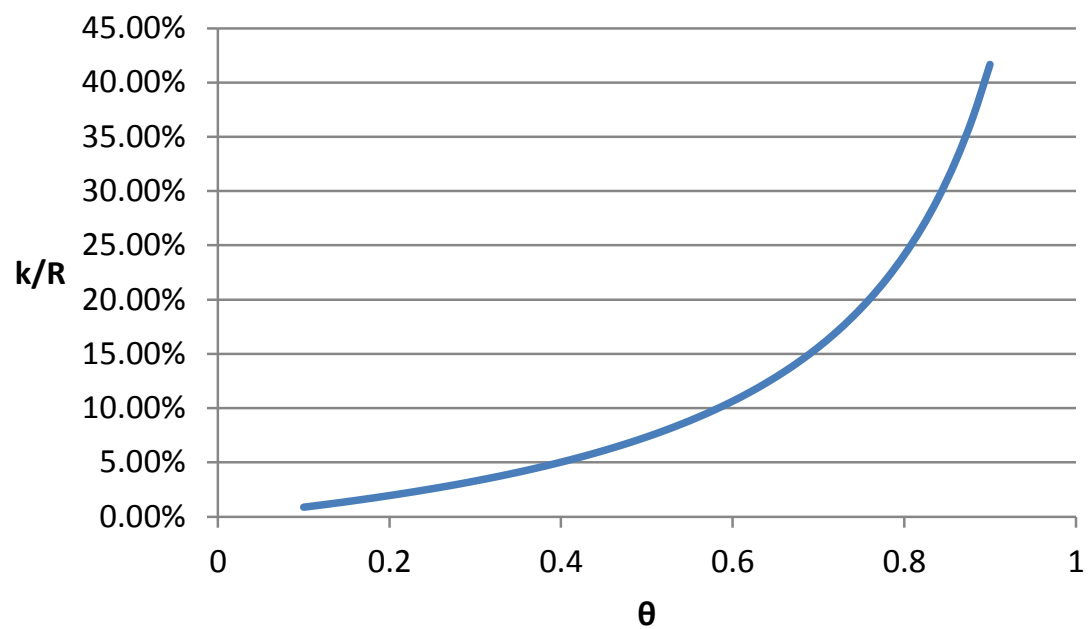

Figure 4. The effect of the investment bank's bargaining power on the investment bank's relative profit

Figure 5 and Figure 6 provide two opposite scenarios to illustrate the effect of the potentially positive initial offer price adjustment $(\mathrm{R})$ on the investment bank's share of profit $(\mathrm{k})$ under the condition that the success arrival rate of IPO is positively related to the initial offer price. (To be noted again that in our model each firm can only issue one share of stock. So R means both the total gross proceeds from the IPO and the initial offer price of the IPO.)

In Figure 5, since the positive size effect of the increase in the initial offer price $\mathrm{R}$ dominates the negative ratio effect of the increase in the success arrival rate $\sigma$, we observe that the investment bank's share of profit k increases with the initial offer price. Figure 5(a) shows that this negative ratio effect and Figure 5(b) shows the net effect (both size effect and ratio effect) of $\mathrm{R}$ on $\mathrm{k}$. The initial offer price ranges from $\$ 0.05$ to $\$ 0.5$ billion, surrounding $\$ 0.2$ billion per IPO transaction. The value of $\$ 0.2$ billion is chosen due to the fact that from 2000 to 2011 there are 1519 offerings with $\$ 352.616$ billion of gross proceeds in total and so the average value of an IPO transaction is $\$ 0.232$ billion $\approx \$ 0.2 \mathrm{billion}$. 

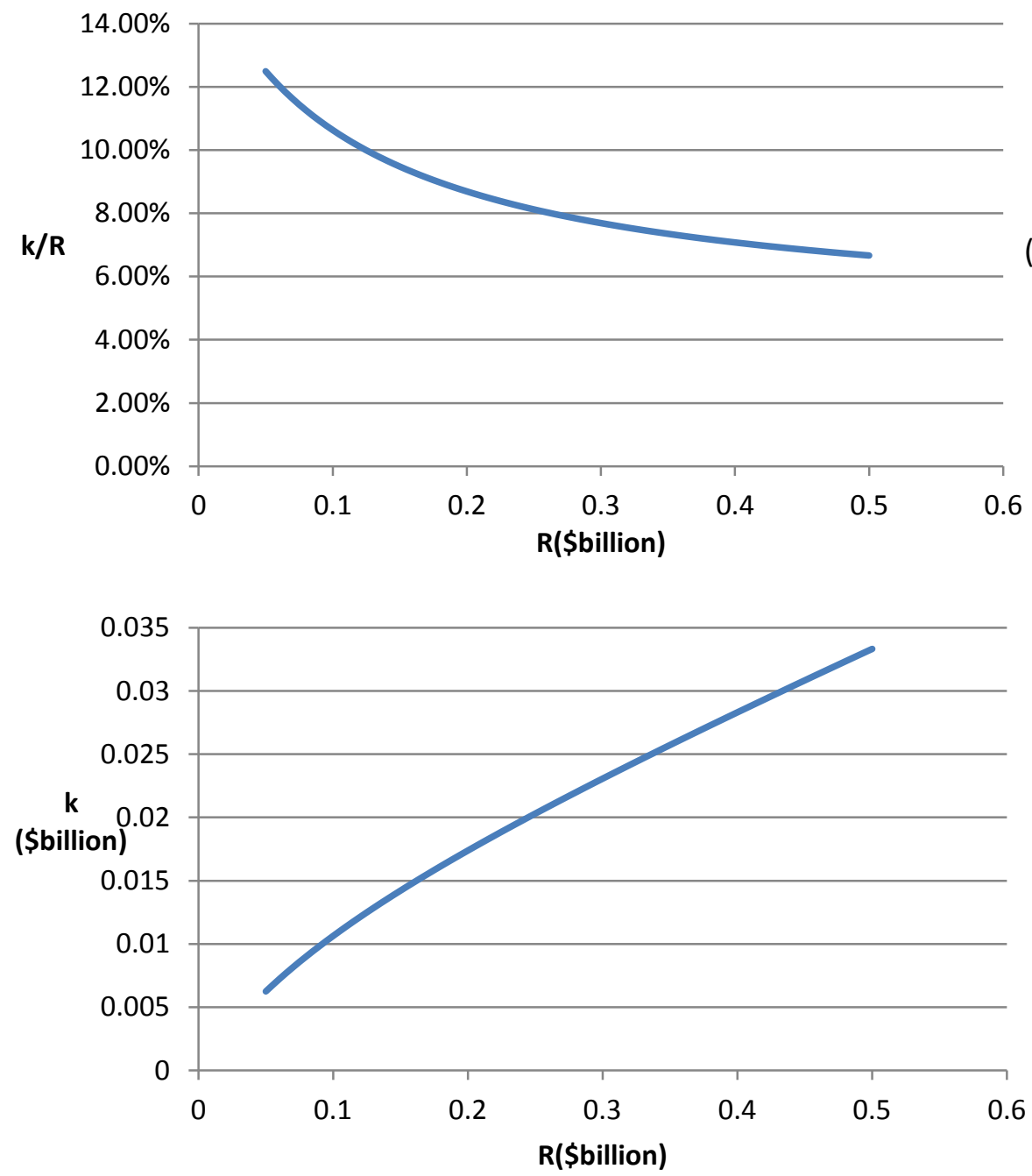

(b)

Figure 5. Scenario one: when the size effect dominates the ratio effect

In Figure 6, since the negative ratio effect of the increase in the initial offer price $\mathrm{R}$ dominates the positive size effect of the increase in the success arrival rate $\sigma$, we observe that the investment bank's share of profit k decreases with the initial offer price. Figure 6(a) shows that this negative ratio effect and Figure 6(b) shows the net effect (both size effect and ratio effect) of $\mathrm{R}$ on $\mathrm{k}$.

The main difference between Figure 5 and Figure 6 comes from the slope linking the co-movement of $\mathrm{R}$ and $\sigma$. Although the values are both positive, the slope used for Figure 6 is about 9 times as large as that used for Figure 5, leading to the totally different net effect of R on $\mathrm{k}$. We cannot overrate the importance of Figure 6(b), which indicates that under our reasonable ranges of parameters, the potentially positive adjustment in the initial offer price may decrease the investment bank's share of profit. For instance, if $\mathrm{R}$ increases from $\$ 0.21$ billion to $\$ 0.23$ billion, $\mathrm{k}$ will decrease from \$0.0163billion to \$0.0156billion in Figure 6(b). This scenario provides a straight-forward search based explanation why the initial offer price only partially adjusts to the positive public information during the IPO price formation stage. In addition, we also find that $\$ 0.237$ billion is a turning point for $\mathrm{R}$ in our case. If the current value of $\mathrm{R}$ is larger than $\$ 0.237$ billion, $\mathrm{k}$ will increase along with the increase in $\mathrm{R}$, which indicates that the over-adjustment (overpricing) is also possible in our simulation. In sum, our model suggests that IPO underpricing is not a deterministic but an empirical phenomenon. 


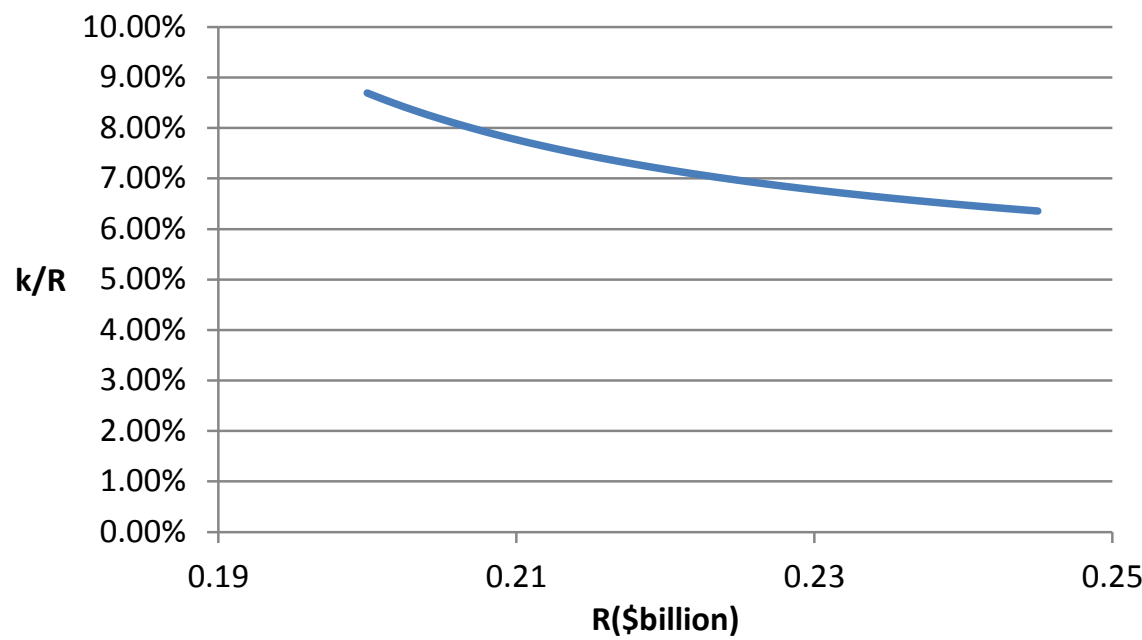

(a)

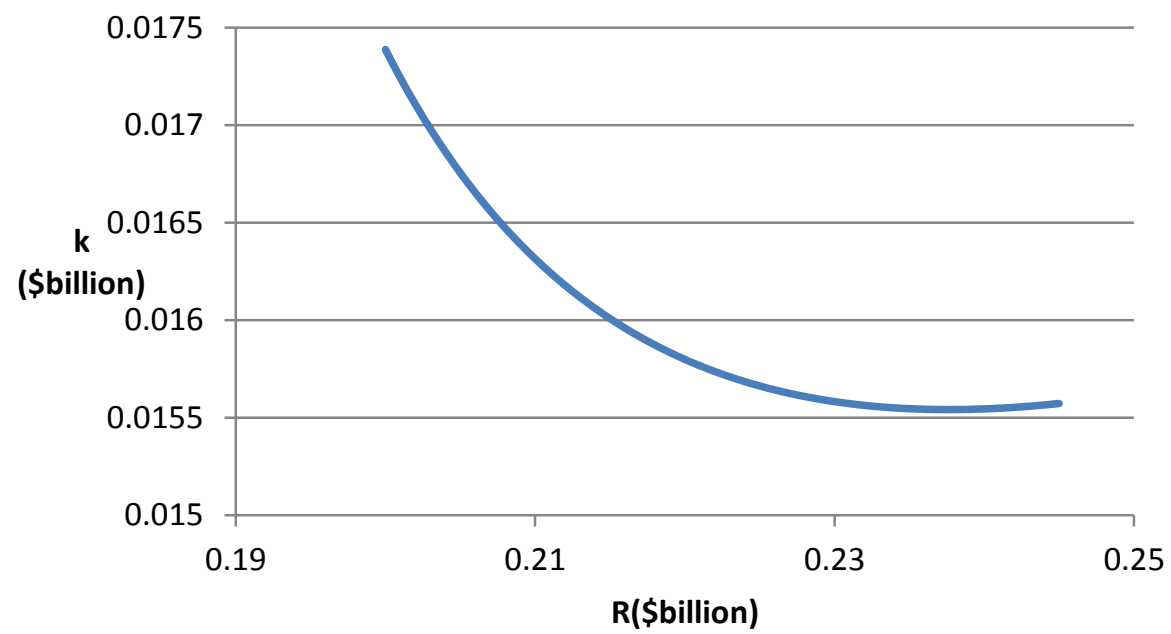

(b)

Figure 6. Scenario two: when the ratio effect dominates the size effect

Basing on Proposition 3, Table 2 provides a general equilibrium picture for the pre-IPO market when the two meeting rates of $\alpha_{\mathrm{f}}$ and $\alpha_{\mathrm{b}}$ are endogenized. Recall that one salient feature of our model is that we focus on the pre-IPO stage, thus making it possible to determine the number of investment banks supported by the underwriting industry endogenously. To our knowledge, few models explicitly consider the market capacity of the underwriting industry. For this purpose, we need to estimate the value of investment banks staying out of the market $(\mathrm{L})$. Here we use the average market value of investment banks, roughly \$20billion as our input. Again we set the initial offer price(R) be $\$ 0.2$ billion here.

Table 2 illustrates that if there are initially 1000 private firms in the market, this market has the capacity of holding 15 investment banks. At the market equilibrium, during each time period 994 private firms and 9 investment banks are continuously searching and 6 strategic pairs have been formed to wait for success. (We assume that one investment bank serves only one private firm in our model). For each successful IPO transaction, the investment bank will earn $\$ 0.0161$ billion, i.e. $7.91 \%$ of the total gross proceeds of each IPO. 
Table 2. General equilibrium picture for the pre-IPO market

\begin{tabular}{lll}
\hline Variable name & Notation & Result \\
\hline The initial number of investment bank & $\mathrm{n}$ & 0.015 \\
The market equilibrium number of IPO pairs & $\mathrm{m}$ & 0.006 \\
The market equilibrium number of investment banks & $\mathrm{n}-\mathrm{m}$ & 0.009 \\
The market equilibrium number of private firms & $1-\mathrm{m}$ & 0.994 \\
The investment bank's share of profit & $\mathrm{k}$ & $\$ 0.0161 \mathrm{billion}$ \\
The investment bank's relative share of profit & $\mathrm{k} / \mathrm{R}$ & $7.91 \%$ \\
The market tightness & $\mathrm{MT}$ & 0.0089 \\
The meeting rate of an investment bank to a private firm & $\alpha_{\mathrm{b}}$ & $10.6 / \mathrm{month}$ \\
The meeting rate of a private firm to an investment bank & $\alpha_{\mathrm{f}}$ & $0.094 / \mathrm{month}$ \\
\hline
\end{tabular}

\section{Conclusion}

In this paper, the optimal strategies of private firms who are eager to go public and investment banks that are assumed to be necessary to serve the IPO process are simultaneously investigated under the framework of two-sided search theory. Four useful value functions for both types of agents are established to represent the corresponding utilities obtained when staying in two distinct states, the searching state and the pair state. One important characteristic of our model is that the intent of every private firm who always wants to go to public is in contrast with the fact that only private firms who indeed form a strategic pair with investment banks can proceed further to a successful IPO.

Aided by this model, the complex IPO process can be reduced into a system with a finite number of equations and a finite number of variables, making the research exploration in IPO areas more tractable. Such IPO related puzzles as IPO short-run underpricing can be creatively explained from the "search" angle. Our model suggests that IPO underpricing is not a deterministic but an empirical phenomenon mainly originating from the market-wide co-movement between the total gross proceeds of each IPO and the total number of successful IPOs, Moreover, our derived closed-form of the investment bank's share of profit from an IPO transaction at the market equilibrium reproduces the "seven percent solution" observed in the underwriting industry.

As the anticipated collapse of the used car market due to the existence of "lemons" by the economist George Akerlof never happened in the U.S., we claim that the market searching structure may be more fundamental than the secondary consideration of asymmetric information. Our perspective is also consistent with Ritter and Welch's (2002) observation that "asymmetric information is not the primary driver of many IPO phenomena".

\section{References}

Baker, M. \& Wurgler, J. (2000). The Equity Share in New Issues and Aggregate Stock Returns. Journal of Finance, 55, 2219-2257. http://dx.doi.org/ 10.1111/0022-1082.00285

Brav, A. \& Gompers, P.A. (2003). The Role of Lock-ups in Initial Public Offerings. Review of Financial Studies, 16, 1-29. http://dx.doi.org/10.1093/rfs/16.1.0001

Carter, R.B., Dark, F.H. \& Singh, A.K. (1998). Underwriter Reputation, Initial Returns, and the Long-Run Performance IPO Stocks. Journal of Finance, 53, 285-311. http://dx.doi.org/10.1111/0022-1082.104624

Chambers, D. \& Dimson, E. (2009). IPO Underpricing over the Very Long Run. Journal of Finance, 64, 1407-1443. http://dx.doi.org/10.1111/j.1540-6261.2009.01468.x

Chen, H.C. \& Ritter, J.R. (2000). The Seven Per Cent Solution. Journal of Finance, 55, 1105-1131. http://dx.doi.org/10.1111/0022-1082.00242

Diamond, P. (1984). A Search-Equilibrium Approach to the Micro Foundations of Macroeconomics. MIT press.

Duffie, D., G^arleanu, N. \& Pedersen, L.H. (2002). Securities Lending, Shorting, and Pricing. Journal of Financial Economics, 66, 307-339. http://dx.doi.org/10.1016/S0304-405X(02)00226-X

Duffie, D., G^arleanu, N. \& Pedersen, L.H. (2005). Over-the-counter markets. Econometrica, 73, 1815-1847. http://dx.doi.org/10.1111/j.1468-0262.2005.00639.x 
Duffie, D., G^arleanu, N. \& Pedersen, L.H. (2007). Valuation in over-the-counter markets. Review of Financial Studies, 20, 1865-1900. http://dx.doi.org/10.1093/rfs/hhm037

Fernando, C.S., Gatchev, V.A. \& Spindt, P.A. (2005). Wanna Dance? How Firms and Underwriters Choose Each Other. Journal of Finance, 60(5), 2437 - 2469. http://dx.doi.org/10.1111/j.1540-6261.2005.00804.x

Hanley, K. W., \& Hoberg, G. (2012). Litigation Risk, Strategic Disclosure and the Underpricing of Initial Public Offerings. Journal of Financial Economics, 103(2), 235-254. http://dx.doi.org/10.1016/j.jfineco.2011.09.006

Ibbotson, R.G. (1975). "Hot Issue” Markets. Journal of Finance, 30, 1027-1042.

Jacquet, N. \& Tan, S. (2007). On the Segmentation of Markets. Journal of Political Economy, 115, 639-64. http://dx.doi.org/10.1086/521967

Kutsuna, K., Smith, J. K., \& Smith, R. L. (2009). Public Information, IPO Price Formation, and Long-Run Returns: Japanese Evidence. Journal of Finance, 64, 505-546. http://dx.doi.org/10.1111/j.1540-6261.2008.01440.x

Lagos, R. \& Rocheteau, G. (2007). Search in asset markets: market structure, liquidity, and welfare. American Economic Review, 97(2), 198-202. http://dx.doi.org/10.1257/aer.97.2.198

Liu, X., \& Ritter, J. R. (2011). Local underwriter oligopolies and IPO underpricing. Journal of Financial Economics, 102(3), 579-601. http://dx.doi.org/10.1016/j.jfineco.2011.01.009

Logue, D. (1973). Premia on Unseasoned Equity Issues, 1965-69. Journal of Economics and Business, 25, 133-141.

Loughran, T. \& Ritter, J.R. (2002). Why Don't Issuers Get Upset About Leaving Money on the Table in IPOs?. Review of Financial Studies, 15, 413-444. http://dx.doi.org/10.1093/rfs/15.2.413

Loughran, T. \& Ritter, J.R. (2004). Why Has IPO Underpricing Changed Over Time?. Financial Management, 33, 5-37.

Lowry, M., Officer, M.S. \& Schwert, G.W. (2010). The Variability of IPO Initial Returns. Journal of Finance, 65, 425-465. http://dx.doi.org/10.1111/j.1540-6261.2009.01540.x

Lucas, D.J. \& McDonald, R.L. (1990). Equity Issues and Stock Price Dynamics. Journal of Finance, 45, 1019-1043. http://dx.doi.org/10.1111/j.1540-6261.1990.tb02425.x

Menzio, G. (2007). A Theory of Partially Directed Search. Journal of Political Economy, 115, 748-76. http://dx.doi.org/10.1086/525544

Mortensen, D.T. \& Pissarides, C.A. (1994). Job Creation and Job Destruction in the Theory of Unemployment. The Review of Economic Studies, 61, 397-415. http://dx.doi.org/10.2307/2297896

Ritter, J.R. \& Welch, I. (2002). A Review of IPO Activity, Pricing, and Allocations. Journal of Finance, 57, 1795-1828. http://dx.doi.org/10.1111/1540-6261.00478

Shimer, R. (2007). Mismatch. American Economic Review, 97, 1074-1101. http://dx.doi.org/10.1257/aer.97.4.1074

Silveira, R. \& Wright, R. (2007). The Venture Capital Cycle. Working paper, University of Pennsylvania.

Vayanos, D. \& Weill, P. (2008). A Search-Based Theory of the On-the-Run Phenomenon. Journal of Finance, 63, 1361-1398. http://dx.doi.org/10.1111/j.1540-6261.2008.01360.x

Yung, C., Çolak, G., \& Wang, W. (2008). Cycles in the IPO market. Journal of Financial Economics, 89, 192-208. http://dx.doi.org/10.1016/j.jfineco.2007.06.007 


\section{Appendix A: Notation Table}

f private firm

b investment bank

1 the initial number of private firms normalized to 1

$\mathrm{n} \quad$ the initial number of investment banks

$\mathrm{m} \quad$ the equilibrium number of IPO pairs

$\alpha_{\mathrm{f}} \quad$ the meeting rate of a private firm to an investment bank, i.e. how many investment banks a private firm can meet during each time period.

$\alpha_{\mathrm{b}} \quad$ the meeting rate of an investment to a private firm, i.e. how many private firms an investment bank can meet during each time period.

$\sigma \quad$ the success arrival rate of IPO

$\mathrm{R}$ the total gross proceeds of an IPO or the initial offer price of an IPO

$\mathrm{k} \quad$ investment bank's share of profit from an IPO

$\mathrm{k}^{*} \quad$ investment bank's share of profit from an IPO at the market equilibrium

State"0" the searching state

State"1" the IPO pair state

$\mathrm{V}_{\mathrm{f}}^{\mathrm{o}}$

$\mathrm{V}_{\mathrm{f}}^{1}$

$\mathrm{V}_{\mathrm{b}}{ }^{0}$

the value of a private firm who is searching an investment bank in the market

$\mathrm{V}_{\mathrm{b}}{ }^{1}$

the value of a private firm who forms a strategic pair with an investment bank

the value of an investment bank who is searching a private firm in the market

$\mathrm{r}$ the value of an investment bank who forms a strategic pair with a private bank the (risk-free) discount rate

$\mathrm{S}_{\mathrm{f}} \quad$ the surplus function for a private firm, equals $\mathrm{V}_{\mathrm{f}}{ }^{1}-\mathrm{V}_{\mathrm{f}}{ }^{\mathrm{o}}$

$\mathrm{S}_{\mathrm{b}} \quad$ the surplus function for a private firm, equals $\mathrm{V}_{\mathrm{b}}{ }^{1}-\mathrm{V}_{\mathrm{b}}{ }^{\mathrm{o}}$

$\theta \quad$ investment bank's bargaining power, the parameter in the general Nash bargaining scheme

MT the market tightness, equals $\frac{\mathrm{n}-\mathrm{m}}{1-\mathrm{m}}$, denotes the relative number of investment bank to private firm at the market equilibrium

$\pi \quad$ the matching technology function between $\mathrm{f}$ and $\mathrm{b}$

$\delta$ the parameter in the matching technology function $\pi$

$\mathrm{L} \quad$ the value of investment banks staying out of the market

\section{Appendix B: Proofs of Propositions}

\section{Proposition 1}

Assuming the outside options $\mathrm{V}_{\mathrm{f}}{ }^{\mathrm{o}}$ and $\mathrm{V}_{\mathrm{b}}{ }^{\mathrm{o}}$ as given, find the expressions of the two surplus functions $\left(\mathrm{S}_{\mathrm{f}}\right.$ and $\left.\mathrm{S}_{\mathrm{b}}\right)$ according to their definitions (5) and (6). The values of those surplus functions depend on $\mathrm{k}$ which is chosen by the bargain process of two parties. Then apply the first order condition to solve the Generalized Nash bargain problem (7) and put the market equilibrium condition (8) into the F.O.C., we can derive the formula for $\mathrm{k}^{*}$.

Specifically, let the outside options $\mathrm{V}_{\mathrm{f}}{ }^{\mathrm{o}}$ and $\mathrm{V}_{\mathrm{b}}{ }^{\mathrm{o}}$ be given:

Consider (2) when the investment bank's share is $\mathrm{k}$,

$$
\begin{aligned}
& \mathrm{V}_{\mathrm{f}}^{1}(\mathrm{k})=\frac{\sigma(\mathrm{R}-\mathrm{k})}{\mathrm{r}+\sigma} \\
& \text { Then, } \quad \mathrm{S}_{\mathrm{f}}(\mathrm{k})=\mathrm{V}_{\mathrm{f}}^{1}(\mathrm{k})-\mathrm{V}_{\mathrm{f}}^{0}=\frac{\sigma(\mathrm{R}-\mathrm{k})}{\mathrm{r}+\sigma}-\mathrm{V}_{\mathrm{f}}^{0}=\frac{\sigma(\mathrm{R}-\mathrm{k})-(\mathrm{r}+\sigma) \mathrm{V}_{\mathrm{f}}^{0}}{\mathrm{r}+\sigma}
\end{aligned}
$$

Consider (4) when the investment bank's share is k, 


$$
\mathrm{V}_{\mathrm{b}}{ }^{1}(\mathrm{k})=\frac{\sigma\left(\mathrm{k}+\mathrm{V}_{\mathrm{b}}^{0}\right)}{\mathrm{r}+\sigma}
$$

Then, $\quad \mathrm{S}_{\mathrm{b}}(\mathrm{k})=\mathrm{V}_{\mathrm{b}}{ }^{1}(\mathrm{k})-\mathrm{V}_{\mathrm{b}}{ }^{0}=\frac{\sigma\left(\mathrm{k}+\mathrm{V}_{\mathrm{b}}^{0}\right)}{\mathrm{r}+\sigma}-\mathrm{V}_{\mathrm{b}}^{0}=\frac{\sigma \mathrm{k}-\mathrm{rV} \mathrm{V}_{\mathrm{b}}^{0}}{\mathrm{r}+\sigma}$

Replace $S_{\mathrm{f}}$ and $\mathrm{S}_{\mathrm{b}}$ by (B-2) and (B46), (7) is changed into:

$\operatorname{Max} \mathrm{S}_{\mathrm{f}}{ }^{1-\theta} \mathrm{S}_{\mathrm{b}}{ }^{\theta}=\operatorname{Max}\left[\frac{\sigma(\mathrm{R}-\mathrm{k})-(\mathrm{r}+\sigma) \mathrm{V}_{\mathrm{f}}^{0}}{\mathrm{r}+\sigma}\right]^{1-\theta}\left(\frac{\sigma \mathrm{k}-\mathrm{r} \mathrm{V}_{\mathrm{b}}^{0}}{\mathrm{r}+\sigma}\right)^{\theta}$

Since $(\mathrm{r}+\sigma)$ are parameters, the above optimal problem is equivalent to:

$\operatorname{Max}\left[\sigma(\mathrm{R}-\mathrm{k})-(\mathrm{r}+\sigma) \mathrm{V}_{\mathrm{f}}^{0}\right]^{1-\theta}\left(\sigma \mathrm{k}-\mathrm{rV}_{\mathrm{b}}^{0}\right)^{\theta}$

Apply the first order condition to (B-6) for $\mathrm{k}$ :

$(1-\theta)\left[\sigma(\mathrm{R}-\mathrm{k})-(\mathrm{r}+\sigma) \mathrm{V}_{\mathrm{f}}^{0}\right]^{-\theta}(-\sigma)\left(\sigma \mathrm{k}-\mathrm{rV}_{\mathrm{b}}^{0}\right)^{\theta}+\left[\sigma(\mathrm{R}-\mathrm{k})-(\mathrm{r}+\sigma) \mathrm{V}_{\mathrm{f}}^{0}\right]^{1-\theta} \theta\left(\sigma \mathrm{k}-\mathrm{rV}_{\mathrm{b}}^{0}\right)^{\theta-1} \sigma=0$

(B-7) is simplified into:

$\sigma \mathrm{k}=\theta \sigma \mathrm{R}+(1-\theta) \mathrm{rV}_{\mathrm{b}}^{0}-\theta(\mathrm{r}+\sigma) \mathrm{V}_{\mathrm{f}}^{0}$

We need to the formulas for $V_{b}^{0}$ and $V_{f}^{0}$, which can be derived from (1)-(4):

(1) $-(4) \rightarrow \mathrm{V}_{\mathrm{b}}{ }^{1}-\mathrm{V}_{\mathrm{b}}{ }^{0}=\frac{\sigma \mathrm{k}^{*}}{\mathrm{r}+\alpha_{\mathrm{b}}+\sigma}$

Put (B-9) back into (3):

$\mathrm{V}_{\mathrm{b}}^{\mathrm{o}}=\frac{\alpha_{\mathrm{b}} \sigma \mathrm{k}^{*}}{\mathrm{r}\left(\mathrm{r}+\alpha_{\mathrm{b}}+\sigma\right)}$

we can also find the expressions of $\mathrm{V}_{\mathrm{f}}{ }^{\mathrm{o}}$ and $\mathrm{V}_{\mathrm{f}}{ }^{1}$ from (1) and (2):

$(2) \rightarrow \mathrm{V}_{\mathrm{f}}^{1}=\frac{\sigma\left(\mathrm{R}-\mathrm{k}^{*}\right)}{\mathrm{r}+\sigma}$

$$
(\mathrm{B}-1) \text { and }(1) \rightarrow \mathrm{V}_{\mathrm{f}}^{\mathrm{o}}=\quad \frac{\alpha_{\mathrm{f}}}{\alpha_{\mathrm{f}}+\mathrm{r}} \mathrm{V}_{\mathrm{f}}^{1}=\frac{\alpha_{\mathrm{f}} \sigma\left(\mathrm{R}-\mathrm{k}^{*}\right)}{\left(\alpha_{\mathrm{f}}+\mathrm{r}\right)(\mathrm{r}+\sigma)}
$$

Putting (B-10) and (B-12) into (B-8), we get:

$$
\begin{aligned}
\sigma \mathrm{k}=\theta \sigma \mathrm{R}+ & (1-\theta) \mathrm{r} \frac{\alpha_{\mathrm{b}} \sigma \mathrm{k}^{*}}{\mathrm{r}\left(\mathrm{r}+\alpha_{\mathrm{b}}+\sigma\right)}-\theta(\mathrm{r}+\sigma) \frac{\alpha_{\mathrm{f}} \sigma\left(\mathrm{R}-\mathrm{k}^{*}\right)}{\left(\alpha_{\mathrm{f}}+\mathrm{r}\right)(\mathrm{r}+\sigma)} \\
& =\theta \sigma \mathrm{R}+(1-\theta) \frac{\alpha_{\mathrm{b}} \sigma \mathrm{k}^{*}}{\mathrm{r}+\alpha_{\mathrm{b}}+\sigma}-\theta \frac{\alpha_{\mathrm{f}} \sigma\left(\mathrm{R}-\mathrm{k}^{*}\right)}{\alpha_{\mathrm{f}}+\mathrm{r}}
\end{aligned}
$$

Divide both sides of (B-13) by $\sigma$ :

$$
\mathrm{k}=\theta \mathrm{R}+(1-\theta) \frac{\alpha_{\mathrm{b}} \mathrm{k}^{*}}{\mathrm{r}+\alpha_{\mathrm{b}}+\sigma}-\theta \frac{\alpha_{\mathrm{f}}\left(\mathrm{R}-\mathrm{k}^{*}\right)}{\alpha_{\mathrm{f}}+\mathrm{r}}
$$

Apply the market equilibrium condition (8) to (B-14):

$\mathrm{k}^{*}=\theta \mathrm{R}+(1-\theta) \frac{\alpha_{\mathrm{b}} \mathrm{k}^{*}}{\mathrm{r}+\alpha_{\mathrm{b}}+\sigma}-\theta \frac{\alpha_{\mathrm{f}}\left(\mathrm{R}-\mathrm{k}^{*}\right)}{\alpha_{\mathrm{f}}+\mathrm{r}}$

Then, $\mathrm{k}=\mathrm{k}^{*}=\frac{\theta \mathrm{r}\left(\mathrm{r}+\sigma+\alpha_{\mathrm{b}}\right)}{\theta \mathrm{r}\left(\mathrm{r}+\sigma+\alpha_{\mathrm{b}}\right)+(1-\theta)(\mathrm{r}+\sigma)\left(\mathrm{r}+\alpha_{\mathrm{f}}\right)} \mathrm{R}$

\section{Corollary 1}

$$
\frac{\partial \mathrm{k}}{\partial \mathrm{R}}=\frac{\theta \mathrm{r}\left(\mathrm{r}+\sigma+\alpha_{\mathrm{b}}\right)}{\theta \mathrm{r}\left(\mathrm{r}+\sigma+\alpha_{\mathrm{b}}\right)+(1-\theta)(\mathrm{r}+\sigma)\left(\mathrm{r}+\alpha_{\mathrm{f}}\right)}>0
$$

From (9), we can do comparative static analysis and find the signs of the following first derivations:

The sign of $\frac{\partial \mathrm{k}}{\partial \alpha_{\mathrm{f}}}$ is negative which is straightforward since $\alpha_{\mathrm{f}}$ only shows up in the denominator of (9)

The sign of $\frac{\partial \mathrm{k}}{\partial \alpha_{\mathrm{b}}}$ is positive which can be seen if we re-arrange (9) as below:

$\mathrm{k}=\mathrm{k}^{*}=\left[1-\frac{(1-\theta)(\mathrm{r}+\sigma)\left(\mathrm{r}+\alpha_{\mathrm{f}}\right)}{\theta \mathrm{r}\left(\mathrm{r}+\sigma+\alpha_{\mathrm{b}}\right)+(1-\theta)(\mathrm{r}+\sigma)\left(\mathrm{r}+\alpha_{\mathrm{f}}\right)}\right] \mathrm{R}$

where $\alpha_{\mathrm{b}}$ only shows up in the denominator of (B-16), but this part has a negative sign in front.

We need to use the formula that: $\left(\frac{\mathrm{x}}{\mathrm{y}}\right)^{\prime}=\frac{\mathrm{x}^{\prime} \mathrm{y}-\mathrm{xy} \mathrm{y}^{\prime}}{\mathrm{y}^{2}}$ to show that the sign of $\frac{\partial \mathrm{k}}{\partial \theta}$ is positive:

$\frac{\partial \mathrm{k}}{\partial \theta}=\frac{\mathrm{r}\left(\mathrm{r}+\sigma+\alpha_{\mathrm{b}}\right)(\mathrm{r}+\sigma)\left(\mathrm{r}+\alpha_{\mathrm{f}}\right)}{\left[\theta \mathrm{r}\left(\mathrm{r}+\sigma+\alpha_{\mathrm{b}}\right)+(1-\theta)(\mathrm{r}+\sigma)\left(\mathrm{r}+\alpha_{\mathrm{f}}\right)\right]^{2}} \mathrm{R}>0$ 


\section{Proposition 2}

Let $R$ be the initial offer price of the IPO and assume $\sigma=\sigma(R)$ and $\frac{d \sigma}{d R}>0$.

Define the coefficient in Equation (9) as $\beta$, then,

$$
\mathrm{k}=\mathrm{k}^{*}=\frac{\theta \mathrm{r}\left(\mathrm{r}+\sigma+\alpha_{\mathrm{b}}\right)}{\theta \mathrm{r}\left(\mathrm{r}+\sigma+\alpha_{\mathrm{b}}\right)+(1-\theta)(\mathrm{r}+\sigma)\left(\mathrm{r}+\alpha_{\mathrm{f}}\right)} \mathrm{R}=\beta \mathrm{R}
$$

Note that $\beta$ is a function of $\sigma$ which is also a function of R, i.e. $\beta=\beta(\sigma)=\beta[\sigma(\mathrm{R})]$.

So $\frac{\partial \mathrm{k}}{\partial \mathrm{R}}=\beta+\frac{\partial \beta}{\partial \sigma} \frac{\mathrm{d} \sigma}{\mathrm{dR}} \mathrm{R}$

Let's check out the sign of $\frac{\partial \beta}{\partial \sigma}$ :

$\frac{\partial \beta}{\partial \sigma}=\frac{\theta(1-\theta) r\left(r+\alpha_{f}\right)\left(-\alpha_{b}\right)}{\left[\theta r\left(r+\sigma+\alpha_{b}\right)+(1-\theta)(r+\sigma)\left(r+\alpha_{f}\right)\right]^{2}}$

Then $\frac{\partial \beta}{\partial \sigma}<0$.

Combining our assumption that $\frac{\mathrm{d} \sigma}{\mathrm{dR}}>0$, the sign of $\frac{\partial \mathrm{k}}{\partial \mathrm{R}}$ in (B-19) cannot be decided since the first item is positive and the second item is negative.

\section{Proposition 3}

Define the market tightness as:

$\mathrm{MT}=\frac{\mathrm{n}-\mathrm{m}}{1-\mathrm{m}}$

The meeting rates of $\alpha_{\mathrm{f}}$ and $\alpha_{\mathrm{b}}$ can be derived as:

$\alpha_{\mathrm{f}}=\pi /(1-\mathrm{m})=(1-\mathrm{m})^{-\delta}(\mathrm{n}-\mathrm{m})^{\delta}=\mathrm{MT}^{\delta}$

$\alpha_{\mathrm{b}}=\pi /(\mathrm{n}-\mathrm{m})=(1-\mathrm{m})^{1-\delta}(\mathrm{n}-\mathrm{m})^{\delta-1}=\mathrm{MT}^{\delta-1}$

Put (13) and (14) into (9), we can get (16):

$\mathrm{k}=\mathrm{k}^{*}$

$=\frac{\theta r\left(\mathrm{r}+\sigma+\mathrm{MT}^{\delta-1}\right)}{\theta \mathrm{r}\left(\mathrm{r}+\sigma+\mathrm{MT}^{\delta-1}\right)+(1-\theta)(\mathrm{r}+\sigma)\left(\mathrm{r}+\mathrm{MT}^{\delta}\right)} \mathrm{R}$

Put (B-10) into (15):

$\mathrm{V}_{\mathrm{b}}{ }^{\mathrm{o}}=\frac{\alpha_{\mathrm{b}} \sigma \mathrm{k}^{*}}{\mathrm{r}\left(\mathrm{r}+\alpha_{\mathrm{b}}+\sigma\right)}=\mathrm{L}$

Replace $\mathrm{k}^{*}$ by (16), $\alpha_{\mathrm{f}}$ by (13) and $\alpha_{\mathrm{b}}$ by (14) in (B-21), we can get (17):

$$
\begin{array}{r}
\mathrm{V}_{\mathrm{b}}{ }^{\mathrm{o}}=\frac{\alpha_{\mathrm{b}} \sigma \mathrm{k}^{*}}{\mathrm{r}\left(\mathrm{r}+\alpha_{\mathrm{b}}+\sigma\right)}=\mathrm{L}=\frac{\mathrm{MT}^{\delta-1} \sigma\left[\frac{\theta \mathrm{r}\left(\mathrm{r}+\sigma+\mathrm{MT}^{\delta-1}\right)}{\theta \mathrm{r}\left(\mathrm{r}+\sigma+\mathrm{MT}^{\delta-1}\right)+(1-\theta)(\mathrm{r}+\sigma)\left(\mathrm{r}+\mathrm{MT}^{\delta}\right)} \mathrm{R}\right]}{\mathrm{r}\left(\mathrm{r}+\sigma+\mathrm{MT}^{\delta-1}\right)} \\
=\frac{\mathrm{MT}^{\delta-1} \sigma \theta \mathrm{R}}{\theta \mathrm{r}\left(\mathrm{r}+\sigma+\mathrm{MT}^{\delta-1}\right)+(1-\theta)(\mathrm{r}+\sigma)\left(\mathrm{r}+\mathrm{MT}^{\delta}\right)}
\end{array}
$$

Let's derive (18)-(21):

Put (13) and (14) into (10), we get:

$(1-\mathrm{m}) \mathrm{MT}^{\delta}=\sigma \mathrm{m}=(\mathrm{n}-\mathrm{m}) \mathrm{MT}^{\delta-1}$

Consider the first equal sign, $\quad \mathrm{m}=\frac{\mathrm{MT}^{\delta}}{\sigma+\mathrm{MT}^{\delta}}$

Then, $1-\mathrm{m}=\frac{\sigma}{\sigma+\mathrm{MT}^{\delta}}$

Consider the second equal sign, $\mathrm{n}-\mathrm{m}=\frac{\sigma}{\mathrm{MT}^{\delta-1}} \mathrm{~m}=\frac{\sigma}{\mathrm{MT}^{\delta-1}} \frac{\mathrm{MT}^{\delta}}{\sigma+\mathrm{MT}^{\delta}}=\frac{\sigma \mathrm{MT}}{\sigma+\mathrm{MT}^{\delta}}$

Use (18) and (20), then, $\quad \mathrm{n}=\frac{\sigma \mathrm{MT}}{\sigma+\mathrm{MT}^{\delta}}+\mathrm{m}=\frac{\sigma \mathrm{MT}}{\sigma+\mathrm{MT}^{\delta}}+\frac{\mathrm{MT}^{\delta}}{\sigma+\mathrm{MT}^{\delta}}=\frac{\sigma \mathrm{MT}+\mathrm{MT}^{\delta}}{\sigma+\mathrm{MT}^{\delta}}$ 